\title{
Labour Force Participation and Family Situation of Married Women
}

\author{
Aspects of economic theory and some observations from Norway \\ 1971-1972 1
}

BY OLAV LJONES

Socio-Demographic Research Unit

Central Bureau of Statistics of Norway

\section{Summary}

In this article we shall primarily discuss relationships between the labour force participation of married women and their family situation. The analysis is based on a theory of choice approach and the framework of such a theory on this approach is outlined. We indicate some special theoretical problems in the analysis of the labour force participation of married women, and comment upon some main types of variables which are assumed to influence this participation.

It is customary to assume that the size and composition of the household are important factors in determining the labour force participation of married women. This is confirmed both in the theoretical discussion and in some preliminary observation results from the Norwegian Labour Force Sample Surveys. In the empirical part of this article only one background variable at a time is taken into account; this represents a limitation since it must be assumed that there is an interaction among the different variables included.

In the final section we discuss briefly some of the problems concerning the simultaneous treatment of labour force status and number of children.

\section{Labour Force Participation of Married Women}

1.1. This analysis is limited to the study of the labour force participation of married women. There are several reasons for confining the study to married women: They represent a population group which has a considerably lower participation rate than others, at the same time that they comprise a large per-

1 The analysis presented here concerning one particular aspect of labour force participation of women has been prepared in conjunction with a larger project in the Central Bureau of Statistics of Norway dealing with women in the labour force in general. I am indebted to Mr. Jan M. Hoem, Mr. Bjørn L. Tønnesen and Mr. Eivind Hoffmann for their valuable comments and advice. 
centage of the total number of women. (About two-thirds of the women in Norway in 1972 between the ages of 16-74 were married.) It will also be reasonable to assume that the situation or conditions for married women on the labour market are of considerable importance to single and previously married women. It is natural to assume that women who have previously been married will be influenced by this experience. It is also conceivable that the marital plans and expectations of younger single women may have an influence on their choice of occupation and education.

Even though the analysis is limited to married women, it will also be relevant for unmarried women who live in a family situation corresponding to the one which is "normal» for married women. Co-habitation without formal marriage (marriage of conscience) has become increasingly more widespread during recent years, particularly in Sweden. This should be taken into account when analyzing the labour force participation of women if information concerning the individual's formal marital status is used as a basis.

1.2. The simple economic theory of labour supply, based on the theory of consumer behaviour as, for example, presented in Serck-Hanssen (1964) and Hendersson \& Quandt (1958), can be said to be a theory of the individual's offer of work. It may possibly also be interpreted as a theory of a household's total labour supply. In analyzing the labour supplied by married women, however, we are not only interested in the household's total labour supply, but also how this work is distributed among family members. It is conceivable that this problem can also be analysed within the framework of a theory of choice. Bowen and Finegan (1969), who include an analysis of the labour force participation of married women in their study, work within the context of a theory of choice. The family is then viewed as a unit which maximizes its utility subject to a resource constraint in such a way that not only the total labour supplied is determined, but the allocation of this among family members as well. In this article I shall not attempt to provide an analytical specification of such a model, but limit the discussion to certain aspects and some of the variables which will be included in the model.

1.3. In the simple theory of labour supply which is described, for example, in Serck-Hanssen (1964) and Henderson \& Quandt (1958), there are two types of activities, work and leisure. This classification will seem unsatisfactory for analysing the labour force participation of married women. Cain (1966) indicates that home work is a particularly important activity for married women. It might thus be appropriate to operate with three types of activities: market work, home work and leisure. (This classification is utilized, for example, in a Norwegian analysis of the labour force participation of married women by Diesen 1970). The classification of work activities into two types, home work and market work, indicates that the model should include not only a description of the conditions on the labour market, but also some type of description of the production process taking place in the home. This will be discussed in more detail later. 
In the two classifications of types of activities mentioned thus far, leisure has been specified as a separate activity. However, it is problematic to give a precise definition of what is to be considered leisure, particularly when home work is viewed as a separate activity. In the case of child care, for example it is obviously difficult to distinguish between child care as home work and being together with one's own children as a leisure activity.

The important point, however, is not the distinction between home work and leisure, but that production takes place in the household and that all activities are time-demanding. The conceptual framework employed by Becker (1965) entails that the household is both a producing and consuming unit, but where leisure does not exist as an independent concept. Even though it may perhaps prove difficult to provide a specification of this theory which can provide the basis for empirical studies, I shall briefly mention some of its main features, inter alia, because elements of this theory have inspired a number of people who have analysed the individual's labour force status during recent years. (Cf., for example, Bowen \& Finegan 1969).

In contrast to the conventional theory of consumer behaviour, Becker does not include the quantities of consumed goods and services directly in the utility function. Instead, Becker uses so-called basic commodities as arguments in the function. These basic commodities, he suggests, are produced in the household through the input of market goods (goods and services purchased) and time. Becker mentions sleep as an example of a basic commodity. To obtain this commodity one requires both time and the input of market goods (bed and bed linens, sleeping pills?). In addition to the time the household spends on producing the basic commodities, some time can be used for market work. Some consumption activities are more time-intensive than others, at the same time that the expenditure component of the input of market goods may vary. Looking after one's own children and cleaning the house are time-intensive, but they may require relatively small outlays for the input of goods.

As in the traditional theory of consumer behaviour, Becker suggests that the household maximizes its utility subject to resource constraints. Within the framework of the theory of choice it can be said that a discussion of the variables which influence the individual's labour force status (the labour supplied) amounts to a discussion of variables that will alter the conditions for optimal behaviour.

1.4. A problem not discussed in most analyses of the labour supplied by married women based on the theory of choice, is how the household determines the hours each household member is to devote to market work or other activities. In theory it is conceivable that this allocation is determined simultaneously for all family members. Becker only touches upon the problem of division of labour in the family in his article.

One possible way of solving the problem in the model is to introduce male and female work in the market as two different types of work. This approach 
is suggested in Diewert (1971). Even though such a distinction will be found to a certain extent in today's labour market, the assumption will possibly be somewhat unrealistic.

The question of how the members of the household distribute the work load must be viewed in connection with the postulate of a utility function for the family and the assumptions on which the utility function are based. The utility function shall in some way weight the utility of each member, and the optimal division of labour will depend on how this weighting is done.

1.5. As mentioned in Section $1.2 \mathrm{I}$ shall not present any precise formulation of a model for analyzing the labour force participation of married women. In this section, however, I shall discuss some main types of variables which would be natural to include in a model based on a theory of choice. The grouping of types of variables is largely based on a classification prepared by Bowen and Finegan, (Ch. 2, 1969).

\section{Expected market earnings}

It is not obvious which is the most relevant wage-concept. A useful concept will be a measure of earnings for labour input which is net in the sense that it takes into account the various types of costs involved in accepting employment. It may also be relevant to consider other nonmonetary aspects of the work as, for example, dirt, noise, whether the work is interesting or provides status.

A person's earnings will depend on a number of factors, including education and previous working experience. The expected earnings will also vary from one place to another. The varying possibilities women have in obtaining employment will be reflected in wages. If a married woman lives in an area where it is assumed to be impossible to obtain work, her expected market earnings in the model would be zero or very low.

There are typical wage differentials between men and women. Each family will take this into consideration when making labour force decisions. Men who have higher expected market earnings than married women will use less time for time-intensive consumption activities than women and more time for market work. Cleaning the house and child care are examples of time-intensive activities (see Section 1.3). Changes in the expected market earnings for one family member may influence the labour force decision of other members. Labour force activities of women can thus be expected to rise if other members of their household experience un-employment.

\section{II »Wages» for home work}

In Section 1.3 we indicated that an analysis of the labour force participation of married women should not only include a description of the labour market 
(the expected market earnings), but that the model should also include a description of the production process in the home. The family's total supply of labour is not only influenced by market earnings, but also what I for the sake of simplicity call »wages» for home work. This is not a measureable variable; it may rather be interpreted as an overall designation for variables which describe the production conditions in the household and the demand for products there. "Wages» for home work will depend on the person's skills in doing these tasks and these skills will depend on previous experience, the kind of work to be done and perhaps by sex as well.

The size and composition of the household will influence, of course, the demand for production in the home, and it is assumed that children in the family will particularly influence this demand.

\section{Family resources}

In Section 1.3 it was mentioned that the theory of choice framework is based on the notion that the family maximizes its utility subject to a resource constraint. This resource constraint will depend on the size and composition of the family and potential market earnings. Moreover, the resource constraint will depend on the prices of market goods. Non-labour income and wealth should also be taken into account. As mentioned previously, the time available to the family ( 24 hours a day per person) is included in the resource constraint.

\section{Tastes}

It is difficult to provide a precise analysis of this type of variable. Let us tentatively say that the variables falling in this category shall reflect to what extent the woman herself or the other family members are influenced by the conventional roles of the sexes in their view of the division of work in the home.

The framework of the traditional theory of choice may be criticized for viewing work hours as a sacrifice, without taking into account other aspects of work as, for example, that it might provide personal satisfaction and social contact. In Becker's analysis, however, it is not really necessary to interpret working hours as a sacrifice, other than that it is time-demanding and thereby reduces the possibilities for consumption activities.

In this article, we shall limit ourselves to examining the results of how the size and composition of the household influence labour force participation. Such a partial analysis of factors influencing labour force activities may be unsatisfactory from a theoretical point of view. However, time has not allowed us to provide a thorough simultaneous discussion of all variables within the framework of this article. 


\section{Labour Force Participation and the Size and Composition of the Household}

\subsection{Data base}

The surveys are made on a quarterly basis and each time are based on a random sample of about 6,000 households, corresponding to a little less than 12,000 persons. The sample includes only persons aged 16-74. The sample is rotating, i.e. members are replaced from one quarter to another according to a definite pattern.

The results presented here are average figures for the two trial surveys for the third and fourth quarter of 1971 and the ordinary surveys of the first and second quarter of 1972. (The scope of both the trial surveys and the ordinary surveys was the same. ${ }^{1}$ )

The dwelling household is used as the household unit in the Norwegian Manpower Survey. Lodgers (persons who rented one-room units) are included in the household even when they do not take their meals with the others.

The following information about the household is collected:

- number of persons in the dwelling unit

- number of sick persons in the dwelling unit

- number of children under 16 years of age in the dwelling unit

- whether preschool children attend a nursery school or day nursery

- whether the household had domestic help and the number of hours the household had domestic help

It should be noted that the survey does not currently include information concerning the interviewed person's position in the household (i.e. family status) and the number of nuclear families in the dwelling household. If, as in our case, we are interested in how the number of children influences the labour force participation of married women, it will be unfortunate that we now do not know whether all the children in the household are the offspring of the married woman being interviewed. Even though the data base therefore cannot be directly used for analysing the relationship between demographic variables as number of children and the labour force participation of married women, it does provide some information on such relationships, particularly if the households generally consist of one nuclear family.

2.2. In the following tables we shall see how the labour force participation rates of married women vary with the size and composition of the household. The participation rate of a population group is defined as the number of persons in the group who are in the labour force as a percentage of the total number of persons in the group. The concept "labour force» is therefore a key element and we shall discuss this a little more.

1 The results have previously been published in Ljones et al. (1973) and Royal Norwegian Ministry of Finance Long-Term Programme 1974-1977. Special analysis 4. Labour force participation $1971-2000$. 
The labour force includes employed persons with paid work, employed persons temporarily absent from paid work, and persons without labour-income looking for work.

All persons who, in the interview, stated that they had paid employment of at least one hour's duration during the survey week were included as employed persons with paid work.

In Section 1.5 we discussed several types of variables which concurrently influence the labour force participation of married women. The analysis presented here must be considered provisional since it only considers one of the groups of variables, i.e. the size and composition of the household. There will be a covariation of the different variables used to describe the size and composition of the household. The simple method of analysis employed here does not permit this interaction of variables to be taken into account.

\subsection{Labour force participation and the number of persons in the household}

When the size of the household increases, the total work load in the home increases as well. It can be said that the demand for home-produced goods and services rises. Larger households will also influence the household's demand for market-produced goods and services, so that the need for labour income may become greater. The household's resource constraint is also influenced by the size of the household. A change in the size of the household thus has several effects which pull in different directions. The change in the labour supply then depends on the strength of these conflicting forces.

The relationship between the labour force participation of married women and the size of the household is shown in Table 1.

T a b le 1. Labour Force Sample Surveys. Participation rates, married women, by the size of the household and the person's age (Average Figures, autumn 1971/spring 1972) ${ }^{1}$.

Size of house-

hold. No. of

persons

1

2

3

4

5

6 and more

Unspecified

Tot a 1

Total
$16-74$
46
42
46
45
41
40
46
43

$20-24$
$:$
81
37
21
23
$:$
$:$
39

\section{A g e}

$25-29 \quad 30-49$

$50-59$

$60-64$

$:$
89
52
36
28
$:$
$:$
44

44

70
58
53
44
43
5

52

$\begin{array}{rr}: & : \\ 48 & 30 \\ 46 & 35 \\ 51 & : \\ 48 & : \\ 50 & : \\ : & : \\ 48 & 32\end{array}$

1 In all the tables in this articles the symbol : means that the figures have not been calculated because of too few observations in the sample. 
We see in Table 1 . that the participation rates of all married women increase somewhat when the size of the household rises from 2 to 3 , while it shows a declining trend with further increases in the size of the household. However, the perhaps somewhat unexpected trend is caused by the figure for the total which obscures such an important background variable as age. When we examine the age-specific participation rates, the situation is quite different. The participation rates diminish as the size of the household increases, particularly for the youngest age group. It is natural to view this in conjunction with the high number of young children in younger households. In the next section we shall see how the participation rates are influenced by the presence of children under 16 years of age.

\subsection{Labour force participation and the number of children under 16 years of age}

The presence of children in a household will create a special demand for goods and services produced at home. However, the demand for market goods and services will also increase. For changes in this variable as well, there will be effects which pull in opposite directions and the change in the labour force status will depend on the strength of these forces (see section 2.3).

Table 2 shows the effect of the number of children under 16 years of age on the labour force participation of married women.

Ta ble 2. Labour Sample Surveys. Participation rates, married women (who live in households consisting of more than one person) by number of children under 16 in the household, and the person's age. (Average figures autumn 1971/spring 1972)1.

$\begin{array}{lcccccc}\begin{array}{l}\text { Number of } \\ \text { children }\end{array} & \text { Total } & \text { A g e } & & \\ \text { under } 16 & 16-74 & 20-24 & 25-29 & 30-49 & 50-59 & 60-64 \\ 0 & 44 & 82 & 86 & 63 & 48 & 33 \\ 1 & 49 & 35 & 51 & 57 & 46 & : \\ 2 & 43 & 16 & 36 & 50 & : & : \\ 3 & 36 & : & 26 & 40 & : & : \\ 4 \text { and more } & 36 & : & 15 & 40 & : & : \\ \text { Unspecified } & 39 & : & : & : & 45 & : \\ \text { Tot a l } & 43 & 39 & 44 & 52 & 48 & 32\end{array}$

1 See Footnote 1, Table 1.

We see in Table 2 that the age-specific participation rates decline when the number of children under 16 increases. This drop in participation rates is particularly pronounced in the youngest age groups. 


\subsection{Labour force participation and age of youngest child}

Not only the number, but also the age distribution of children under 16 years of age in the household has a sizable influence on the participation rate of married women. In general, younger children require more care than older children.

In the labour force sample survey the information on the age distribution of children is limited to the youngest child in the household. Table 2.3 shows the relationship between the age of the youngest child and the labour force activities of married women.

$\mathrm{T}$ a ble 3. Labour Force Sample Surveys. Participation rates, married women who live in households with children under 16, by age of youngest child and the person's age (Average figures autumn 1971/spring $1972)^{1}$

Age of youngest child

$0-2$

$3-6$

$7-10$

$11-15$

Unspecified

Tot a 1
Total

(Age 16-74)

30

42

52

57

58

43

$20-24$
23
37
$:$
$:$
$:$
26

26
A g e

$\begin{array}{ccc}25-29 & 30-49 & 50-59 \\ 32 & 35 & : \\ 44 & 43 & : \\ : & 53 & : \\ : & 60 & 53 \\ : & : & 48\end{array}$

1 See Footnote 1, Table 1.

Table 3 shows that the participation rates of married women increase when the age of the youngest child in the household increases. Note that many groups have become too small to make any calculations. This is due to the covariation between the age of the youngest child and the age of the married woman.

2.6. Labour force participation and placement of children in day nurseries and nursery schools

The relationship between labour force participation and the presence of children in the household is influenced by the possibilities for covering the requirement for child care through outside help. The placement of pre-school children in nursery schools or day nurseries, or arranging for a daily babysitter, will represent possible ways of solving part of the household's requirement for child care. Nursery schools and other such institutions may also be an added educational opportunity for children. 
The participation rates of married women based on whether or not they have children in day nurseries are calculated in Table 4.

T a b le 4. Labour Force Sample Surveys. Participation rates. Married women with children under 16 in the household, according to whether they have children in day nurseries, ${ }^{1}$ by age of youngest child and the person's age. (Average figures autumn 1971/spring 1972)

\begin{tabular}{|c|c|c|c|c|}
\hline & \multirow{2}{*}{$\begin{array}{c}\text { Age of } \\
\text { youngest } \\
\text { child }\end{array}$} & \multirow{2}{*}{$\begin{array}{c}\text { Total } \\
\text { (Age } \\
16-74)\end{array}$} & \multicolumn{2}{|c|}{$\mathrm{Age}$} \\
\hline & & & $25-29$ & $30-49$ \\
\hline \multirow{2}{*}{$\begin{array}{l}\text { Have children in } \\
\text { day nurseries }\end{array}$} & $0-2$ & 57 & 60 & 63 \\
\hline & $3-6$ & 65 & 67 & 61 \\
\hline \multirow{2}{*}{$\begin{array}{c}\text { Do not have children } \\
\text { in day nurseries }\end{array}$} & $0-2$ & 26 & 26 & 31 \\
\hline & $3-6$ & 38 & 39 & 40 \\
\hline
\end{tabular}

1 In this table the term "day nurseries» includes day nurseries, nursery schools and paid babysitters.

It is natural to consider the use of day nurseries and labour force participation as the object of a simultaneous decision taken by the household. Table 4 shows that in those households where there are children aged $0-6$ who are placed in day nurseries, the labour force participation rates of married women are considerably higher than in those households which do not have children in day nurseries.

\section{Simultaneous Analysis of Labour Force Participation and the Demographic Variables}

3.1. The theoretical framework in chapter 1 of this article was based on a static theory of choice approach. It was reasoned that the household makes its decision at one point of time exclusively on the basis of conditions surrounding the household at that particular time. The number of children, education, place of residence appear exogenously in such a model and influence the labour force participation of married women.

While children are usually regarded as one of the determinants of labour force participation of married women in most manpower models, the situation is often reversed in analyses of female fertility, where labour force participation is used as a variable for explaining number of children.

Cain $(1966,9)$ mentions that the work supplied by married women and number of children in the family can be interpreted as endogenously determined by the independent (exogenous) variables, family income and market wages of married women. Cain maintains, however, that in cross-section ana- 
lyses we can consider the number of children as determined at an earlier point of time, and thus as an exogenous variable. In time series analyses, however, it is somewhat more uncertain what justification can be given for interpreting number of children exogenously. Cain maintains that the number of children must be »unplanned» in order for this to be considered an independent magnitude in the model.

3.2. When the value of the variables labour force participation and, for example, number of children, education and place of residence, is viewed as a result of a decision taken by the family, a dynamic model should be used where all the variables mentioned appear as endogenous magnitudes. A dynamic analysis makes it possible to take into account the family's decisions at various points of time as a whole. Such a simultaneous treatment of the variables may clarify questions relating to cause/effect problems and serve as an aid in demographic forecasting.

It will obviously be difficult to prepare a dynamic model which can be applied to an empirical analysis of the decisions in the household. In particular it will probably prove difficult to obtain relevant data. For practical reasons it may thus be appropriate to work with partial and static models for analysing restricted problems such as labour force activities.

\section{References}

Bowen, William G. and T. Aldrich Finegan. The Economics of Labor Force Participation. Princeton University Press, 1969.

Cain, Glen. Married Women in the Labor Force. University of Chicago Press, 1966.

Serck-Hanssen, Jan. Teorier for konsumentenes atferd (Theories of Consumer Behaviour), Norwegian University Press, Oslo, 1964. In Norwegian only.

Henderson, James M. and Richard E. Quandt. Microeconomic Theory. A mathematical approach. McGraw Hill, 1958.

Diesen, Andreas. Tilbudet av gift kvinnelig arbeidskraft. (Supply of labour of married women), Arbeidsnotat 10 70/1, Central Bureau of Statistics, Oslo, 1970. In Norwegian only.

Becker, Gary S. »A theory of the allocation of time». The Economic Journal, September, 1965, pp. 493-517.

Diewert, W. E. Choice on labour markets and the theory of the allocation of time. Research Branch. Program Development Service. Department of Manpower and Immigration, Canada, 1971.

Ljones, Olav, Stein Østerlund Petersen and Bjørn L. Tønnesen. Beregninger over aktuell og framtidig yrkesaktivitet i tilknytning til arbeidet med Langtidsprogrammet 1974-1977. En dokumentasjon. (Calculations of current and future labour force participation in conjunction with the preparation of the Long-Term Programme 1974/1977.) Arbeidsnotat $1073 / 11$, Central Bureau of Statistics, Oslo, 1973. In Norwegian only.

Royal Norwegian Ministry of Finance. Long-Term Programme 1974-1977. Special analysis 4. Labour force participation 1971-2000. Special annex 4 of Parliamentary Report no. 71 1972-73, Oslo 1973. In Norwegian only. 